\title{
Intermediate filaments in synovial lining cells in rheumatoid arthritis and other arthritides are of vimentin type
}

\author{
O. A. OSUNG, M. CHANDRA, AND E. J. HOLBOROW
}

From the Bone and Joint Research Unit, The London Hospital Medical College, 25-29 Ashfield Street, London E1 $2 A D$

SUMMARY Cryostat sections of synovial tissue from patients with rheumatoid arthritis, ankylosing spondylitis, osteoarthrosis, pigmented villonodular synovitis, and from a normal knee were studied by indirect immunofluorescence with guinea-pig antibodies to the intermediate filament proteins prekeratin, vimentin, and desmin. Staining for vimentin, but absence of prekeratin and desmin, was demonstrated in synovial lining cells. Antivimentin antibody also stained synovial tissue fibroblasts and vascular endothelial lining cells. The intensity of fluorescent staining for vimentin broadly correlated with cellular proliferative activity at these 3 sites.

The cytoskeleton of eukaryotic cells comprises filaments of different diameters, namely, microfilaments $(5-6 \mathrm{~nm})$, microtubules $(20-25 \mathrm{~nm})$, and intermediate filaments (IMF) $(8-12 \mathrm{~nm})$. Although the different types of intermediate filaments share certain common physical properties, ${ }^{12} 5$ classes of these filament proteins are distinguishable biochemically and immunologically. These are prekeratin in epithelial cells, desmin or skeletin in muscle cells, vimentin in mesenchymal cells, and neurofilaments and glial filaments in the nervous system.

In view of a report by Ghadially and Roy ${ }^{3}$ that synovial lining cells and vascular endothelial cells in rheumatoid joints have unusually well-marked cytoskeletal fibrillar structures on ultrastructural examination, and of our finding reported in the preceding paper of a high incidence of antibody to IMF in rheumatoid arthritis, ${ }^{4}$ we have examined cryostat sections of synovial tissue from patients for reactivity with anti-IMF protein antisera by indirect immunofluorescence.

\section{Materials and methods}

Tissue. Synovial tissue specimens were obtained at operation for knee joint replacement from 6 patients with classical rheumatoid arthritis and 2 with osteoarthrosis, and at operation for hip replacement

Accepted for publication 20 February 1981. Correspondence to Professor E. J. Holborow. from 1 patient with ankylosing spondylitis. Synovial tissue was also obtained from a patient with pigmented villonodular synovitis undergoing knee joint synovectomy. A specimen obtained from an apparently normal knee joint at post-mortem within 6 hours of death was also examined. The tissues were embedded in OCT (Tissue Tek II), snap-frozen at the temperature of liquid nitrogen, and stored at $-70^{\circ} \mathrm{C}$. $6 \mu \mathrm{m}$ cryostat sections were cut from these tissue blocks, transferred to microscope slides and air dried, fixed in cold acetone $\left(-20^{\circ} \mathrm{C}\right)$ for 5 minutes, and stained by indirect immunofluorescence with specific antisera. Some cryostat sections were fixed in acetone and stained with haematoxylin and eosin.

Specific antisera against intermediate filament proteins. Guinea-pig antisera against bovine prekeratin, desmin prepared from chicken gizzard, vimentin prepared from murine 3T3 cells, and human vimentin prepared from SV40 transformed human skin fibroblasts were gifts from Professor W. W. Franke, Division of Membrane Biology, German Cancer Research Centre, Heidelberg, West Germany.

Indirect immunofluorescence. Drops of the guineapig antisera diluted 1:40 were placed on the acetone-fixed $6 \mu \mathrm{m}$ cryostat sections of synovial tissue. After 45 minutes at $37^{\circ} \mathrm{C}$ the slides were washed in phosphate buffered saline and stained with rabbit anti-guinea-pig immunofluorescent conjugated Ig at a dilution of $1: 30$. After washing in 
phosphate buffered saline ( $\mathrm{pH} 7 \cdot 2)$, the preparation was mounted in glycerol phosphate buffer $(9: 1)$ and examined with a Reichert microscope equipped for transmitted dark-ground illumination. The light source was a $100 \mathrm{~W}$ quartz-halogen lamp, primary filter Balzer FITC-3, secondary filter Ilford $\mathbf{1 1 0 .}$

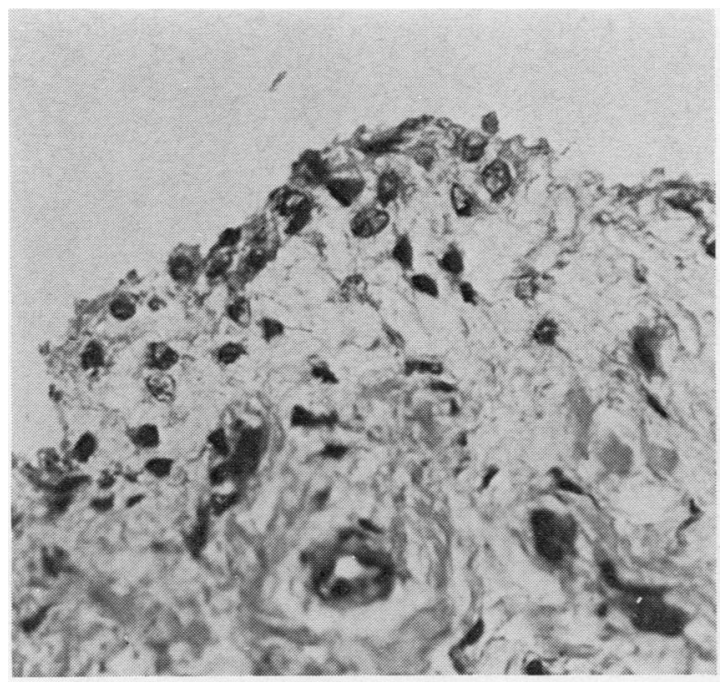

Fig. 1 Acetone-fixed cryostat section of rheumatoid synovial membrane, showing lining-cell proliferation. (Haematoxylin and eosin; $\times 125$, enlarged $\times 3$ ).

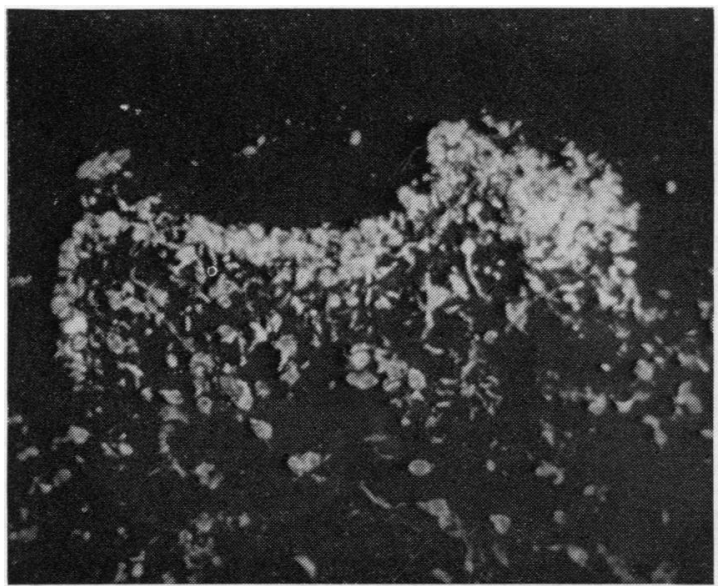

Fig. 2 Cryostat section of rheumatoid synovial membrane, acetone fixed and stained by immunofluorescence with guinea-pig antivimentin (3T3), showing bright fluorescence of proliferating lining cells and deeper fibroblasts. $(\times 96$, enlarged $\times 2)$.

\section{Results}

The synovial membrane in the rheumatoid specimens showed characteristic proliferation with multilayered synovial lining cells (Fig. 1). With antivimentin serum the synovial lining cells in all 6 specimens

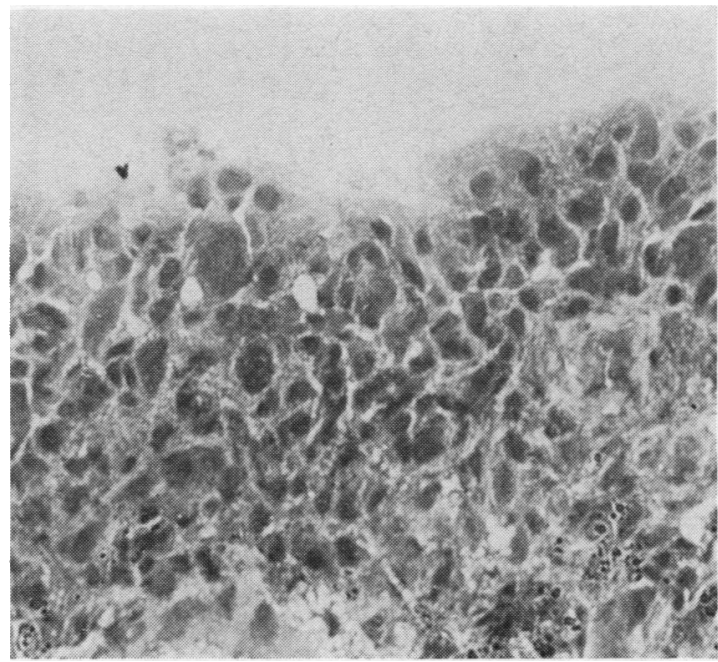

Fig. 3 Acetone-fixed cryostat section from pigmented villonodular synovitis, showing marked lining cell proliferation and pigment deposits in the deeper layers. $(H$ and $E, \times 125$, enlarged $\times 3)$.

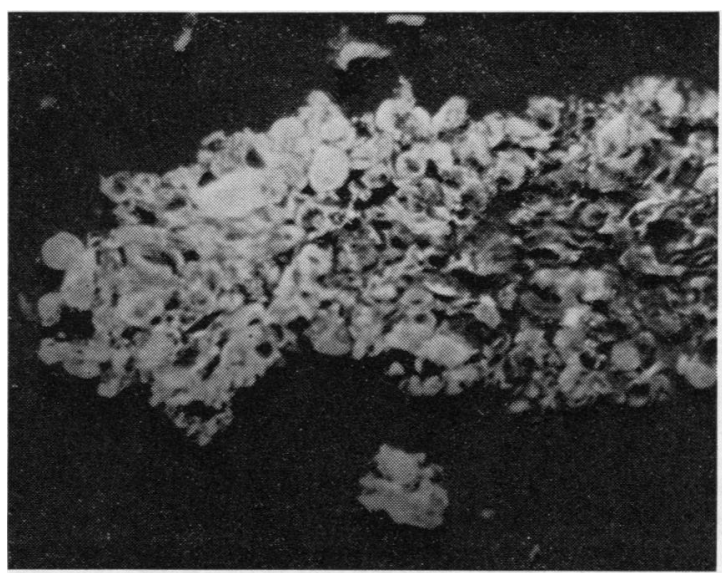

Fig. 4 Villus in a cryostat section of pigmented villonodular synovitis, acetone fixed, and stained by immunofluorescence with antivimentin (3T3), showing bright fluorescence of proliferating lining cells. $(\times 96$, enlarged $\times 2$ ). 
showed bright fluorescent cytoplasmic staining (Fig. 2) with brighter perinuclear areas, and in some cells fine fibrils radiating from the nuclear areas were noted. Similar staining was obtained with both the antimurine and antihuman vimentin antisera.

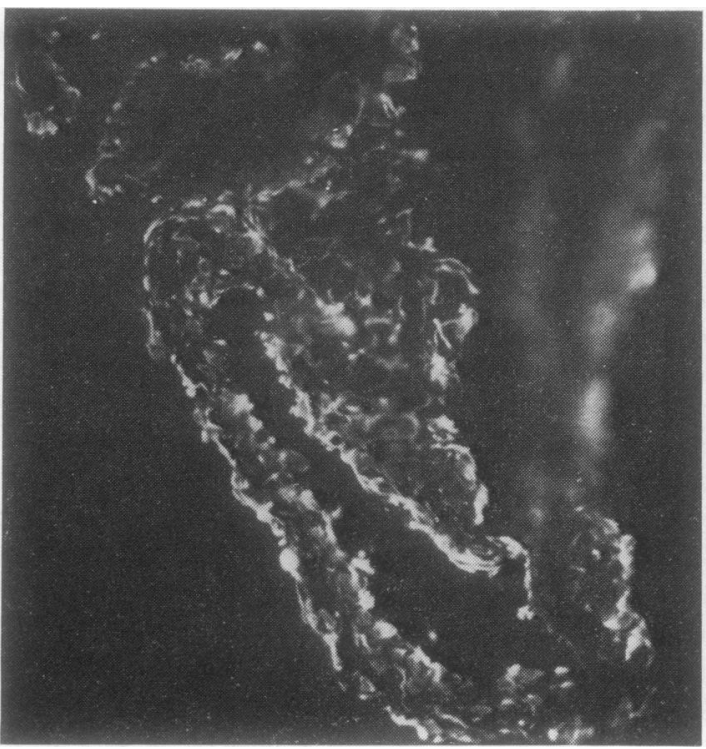

Fig. 5 Cryostat section, acetone fixed, from osteoarthrotic synovial membrane. Minimal proliferation of lining cells, which stain only moderately with antivimentin $(3 T 3)$. $(\times 96$, enlarged $\times 2 \cdot 3)$.

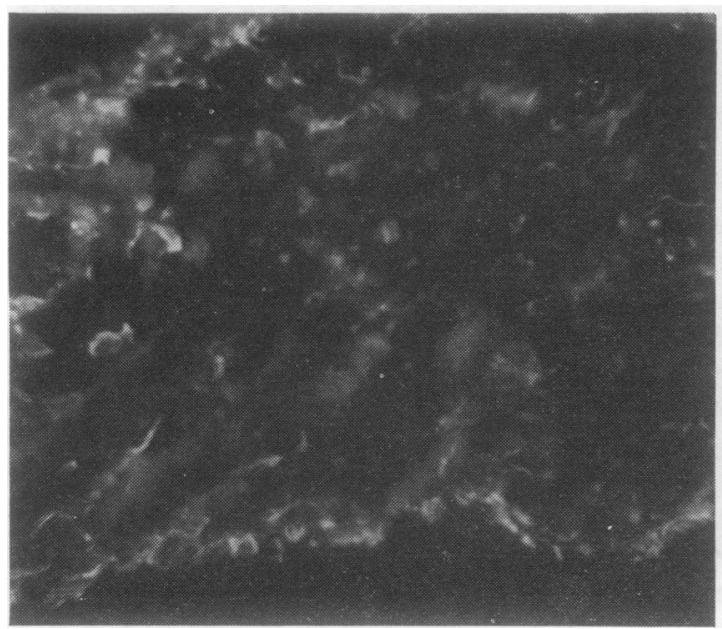

Fig. 6 Normal knee synovial membrane, cryostat section, acetone fixed. Lining cells show little or no staining with antivimentin $(3 T 3)$. $(\times 96$, enlarged $\times 2)$.
In the villonodular synovitis specimen synovial lining cell proliferation was very marked, and the specimen showed sheets of cells with compressed scanty connective tissue (Fig. 3). The synovial cells stained brilliantly with antivimentin sera (Fig. 4). In the specimens from ankylosing spondylitis, osteoarthrosis (Fig. 5), and from the normal knee (Fig. 6)

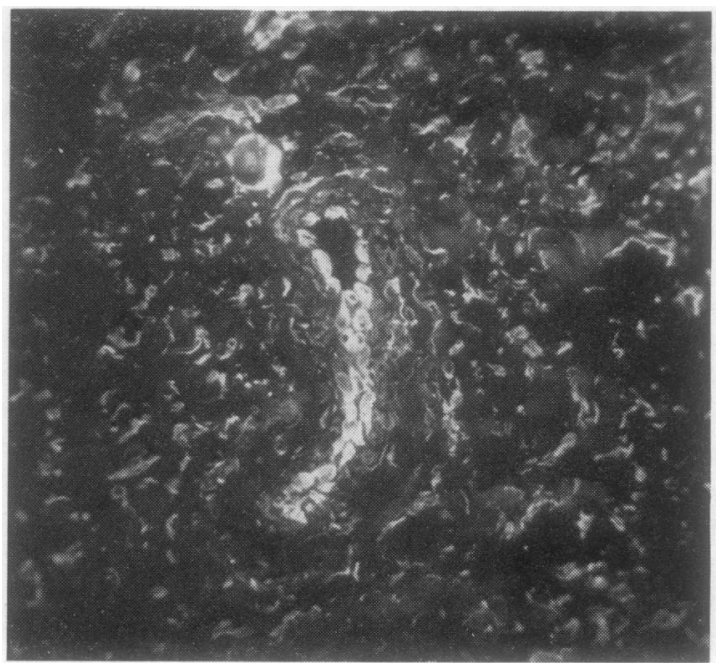

Fig. 7 A small blood vessel in rheumatoid synovial tissue showing marked staining of endothelial cells by antivimentin antisera. Fibroblasts also show staining. $(\times 96$, enlarged $\times 2)$.

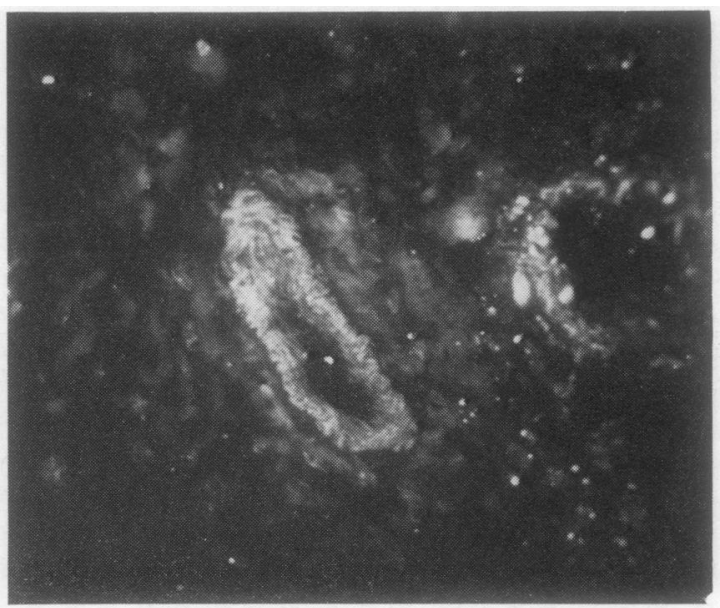

Fig. 8 A small blood vessel in rheumatoid synovial tissue stained with antidesmin antiserum. Smooth muscle coat stained, but endothelium and surrounding fibroblasts negative. $(\times 96$, enlarged $\times 2)$. 
the degree of proliferation of synovial cells varied from moderate to normal, and their cytoplasmic staining with antivimentin showed a corresponding variation from moderate brightness to almost negative. In rheumatoid synovial membrane antivimentin also gave marked staining of vascular endothelial lining cells (Fig. 7). Antidesmin and antikeratin antisera did not stain synovial lining cells, fibroblasts, or vascular endothelium in any of the specimens examined. However, antidesmin stained the muscle coat of blood vessels (Fig. 8).

Serum specimens from the patients undergoing joint replacement were not available. However, serum was taken from the patient with pigmented villonodular synovitis at the time of operation, and when tested on monolayers of human fetal skin fibroblasts (as described in the preceding paper) gave no staining of intermediate filaments.

\section{Discussion}

We have showed that proliferating synovial lining cells contain vimentin as a prominent constituent and that prekeratin and desmin are not demonstrable in these cells. The staining of synovial lining cells with antivimentin was not exclusive to rheumatoid arthritis, since brilliant staining was also seen in pigmented villonodular synovitis. In the other joint conditions studied the staining intensity of cells in the synovial tissue was less marked, and it correlated broadly with the degree of synovial cell proliferation.

A striking finding in this study was that the serum from the villonodular synovitis patient contained no demonstrable anti-IMF antibody despite the marked degree of synovial cell proliferation present in this case. Although sera from the other patients in this study were not available for testing, the findings reported in the preceding paper make it likely that the majority of the rheumatoid arthritis patients had anti-IMF antibody.

One explanation of these findings is that in rheumatoid arthritis (RA) an immunogenic factor in addition to synovial cell proliferation enhances the immunogenicity of IMF protein in the affected synovial tissue in RA, and hence the production of antivimentin antibody. The presence of anti-IMF antibody in the synovial fluid of patients having the antibody in their serum also suggests this. The finding by Mellbye et al. ${ }^{5}$ of oligoclonal smooth muscle antibody (SMA) in synovial fluids of seronegative polyarthritis patients also provides support for the notion that cytoskeletal components in the cells of joint tissues may acquire autoimmunogenicity.

These preliminary findings suggest that the presence of anti-IMF antibodies in rheumatoid serum and synovial fluid may be linked with an undue prominence and immunogenicity of intermediate filaments in mesenchymal cells of the rheumatoid synovial membrane. Further studies of synovial tissues from arthritic and normal joints are being undertaken to test this association and to define more precisely the cytoskeletal components involved.

\section{References}

1 Small J V, Sobieszek A. Studies on the function and composition of $10 \mathrm{~nm}(100-\AA)$ filaments of vertebrate smooth muscle. J Cell Sci 1977; 23: 243-68.

2 Franke W W, Schmidt E, Osborn M, Weber K. Structure and composition of isolated filaments. Cytobiologie 1978; 17: 392-411.

3 Ghadially F N, Roy S. Ultrastructure of synovial membrane in rheumatoid arthritis. Ann Rheum Dis 1967; 26: 426-42.

4 Osung O A, Chandra M, Holborow E J. Antibody to intermediate filaments of the cytoskeleton in rheumatoid arthritis. Ann Rheum Dis in press.

5 Mellbye O J, Fyrand O, Brath H K, Olsen E. Oligoclonal immunoglobulin and smooth muscle antibodies in arthritic joints. Clin Exp Immunol 1980; 40: 103-10. 